\title{
The business of planet management
}

Euan G. Nisbet

Decisions made about the world's economy have consequences for Earth's climate. At their forthcoming meeting in Toronto, the leaders of the West must take that into account.

WHEN the leaders of seven Western nations meet next week in Toronto (19-21 June), they will be largely concerned with planning economic growth. But the scale of the global economy is now so great that they will implicitly also be planning the future of the Earth's atmosphere and of our climate. Should not the West's leaders look to the climatological consequences of their decisions?

The effects of human activities on the environment of our planet are much discussed but poorly understood. But we do know that the atmospheric concentrations of the greenhouse gases, especially $\mathrm{CO}_{2}$, $\mathrm{CH}_{+}$and the chlorofluorohydrocarbons (CFCs) are increasing, with the prospect that the radiative consequences by 2030 will be the equivalent of a doubling of $\mathrm{CO}_{2}$ from pre-industrial concentrations.

Global warming may have been retarded by the thermal inertia of the oceans, but may now be perceptible. Political leaders at Toronto might note that some of the effects of global warming - a sharp reduction of soil moisture in midcontinental North America, for example - will have electoral implications. And who will be blamed for the consequences of a rise of sea level for coastal communities?

\section{Deforestation}

The rapid deforestation of the tropics, especially Amazonia and the East Indies, is similarly alarming, because the forests are regulators of the atmospheric transfer of latent heat and moisture as well as processors of trace gases. Yet by planning for economic growth, the leaders at Toronto, unless they take thought, will be accelerating the rate of fossil fuel consumption and of deforestation. But to abate economic growth would be electoral suicide. Trapped, the Toronto leaders may defer the issue. They need to be offered alternatives.

Unless we are prepared to face the surprises of living in an atmosphere in which $\mathrm{CO}_{2}$ has effectively been doubled, we have little choice but to abandon fossil fuel. Solar power and nuclear fusion are in the long run the most attractive alternatives, but neither can yet supplant fossil fuels, while hydropower has already flooded too much land. Only the nuclearhydrogen economy offers an immediate escape: nuclear power can generate electricity to meet society's main need for energy as well as for the production of hydrogen to fuel vehicles and remote machines. Properly and safely designed, such an economy would eliminate acid rain and allow $\mathrm{CO}_{2}$ and $\mathrm{CH}_{4}$ to fall to managed levels.

Nuclear power is deeply and deservedly unpopular, but the safety problems would be soluble if society would adopt a philosophy of passive safety rather than of maximum profit. The disposal of nuclear waste is a serious matter but, to a geologist, minor compared with the disposal of waste from coal. Perhaps the summit (and the rest of us) should consider how present patterns of energy use must seem to the developing countries. By continuing to burn oil and coal, thereby dispersing $\mathrm{CO}_{2}$ around the globe, instead of facing the problems of handling nuclear power locally, the industrialized nations risk the reputation of playing fast and loose with the fates of poorer nations.

Hydrogen is the obvious currency of clean energy. Interestingly, in the late 1960s, Rhodesia (now Zimbabwe), with abundant electricity, seriously considered switching to a hydrogen economy only to discover that it lacked the industrial base for such an enterprise. But in the industrialized nations of the world, a switch from oil to hydrogen would be comparatively simple, would be profitable and would contribute to the long-term security of Western nations. Automobiles, after all, have an average life of a decade or less, and Detroit is used to periodic redesign and retooling. Without undue dislocation, the West's transport could be cleanly fuelled by 2000 .

The forests present a different problem. Within 25 years, a large part of the forests of Amazonia and the East Indies will have gone. Much of the deforestation is the result of activities of large companies encouraged by government incentives (as in Borneo and Brazil, for example). Given government policies, the companies cannot be blamed. Western nations would do well to express their alarm in the strongest terms. They might also gently remind the Muslim nations of the East Indies of Muhammad's command to plant a tree "though the world end tomorrow".

But why not use the most powerful instrument for saving the tropical rainforests - third world debt? Most of the West's commercial banks wrote down the value of their loans to developing coun- tries in 1987 , but the debtors have so far been offered very little relief. In exchange for tax relief to the banks on their losses, the written-down debts could be transferred to central governments, which could then negotiate with developing countries (Brazil and Indonesia in particular) to cancel the debts in return for the preservation of the rainforests. Privately financed moves along the same lines should be encouraged. More generally, Western governments should consider buying debt from their banks and exchanging it for environmental protection in the tropics. The matter is urgent.

\section{Observatories}

There is still more that can be done. The International Geosphere-Biosphere Programme (IGBP), which is the successor to the International Geophysical Year (IGY) and is now in its planning stages, includes among its proposals a scheme for a network of sophisticated GeosphereBiosphere observatories. This is an enterprise whose cost is modest compared with the investments governments make in freeways, but which could assist enormously in the proper management of the Earth. IGBP deserves more than mere lukewarm approval at Toronto next week - it needs to receive active support and encouragement.

We are at a curious turning-point. The summit will be largely concerned with the global economy, which seems to be in reasonably good shape. At least in the prosperous nations, wealth continues to increase. But should not those at the meeting also pay attention to the longterm threats to the global economy represented by the prospect of climatic change? Is it not their duty, if only for economic reasons, to make a start on the proper management of the Earth?

But, the politicians will say, the scientific evidence for impending climatic change is not yet conclusive. That overlooks the truth that the dangers of inaction substantially outweigh the costs of action, not to mention the general conviction among scientists that the time has come to retreat from present policies. Is it too much to ask that the seven people meeting at Toronto next week should begin to see their problem (and ours) in that light?

Euan G. Nisbet is in the Department of Geological Sciences, University of Saskatchewan, Saskatoon, Saskatchewan S7N OWO, Canada. 